\title{
Multiaxial Fatigue Life Assessment of Integral Concrete Bridge with a Real-Scale and Complicated Geometry Due to the Simultaneous Effects of Temperature Variations and Sea Waves Clash
}

\author{
Hamid Abdollahnia ${ }^{1}$, Mohammad Hadi Alizadeh Elizei ${ }^{1}$ and Kazem Reza Kashyzadeh ${ }^{2, *(D)}$ \\ 1 Department of Civil Engineering, Roudehen Branch, Islamic Azad University, Roudehen 3973188981, Iran; \\ h.abdollahnia@gmail.com (H.A.); alizadeh.mh@riau.ac.ir (M.H.A.E.) \\ 2 Department of Transport, Academy of Engineering, Peoples' Friendship University of \\ Russia (RUDN University), 6 Miklukho-Maklaya Street, 117198 Moscow, Russia \\ * Correspondence: reza-kashi-zade-ka@rudn.ru or kazem.kashyzadeh@gmail.com
}

\section{check for}

updates

Citation: Abdollahnia, H.; Alizadeh Elizei, M.H.; Reza Kashyzadeh, K. Multiaxial Fatigue Life Assessment of Integral Concrete Bridge with a Real-Scale and Complicated Geometry Due to the Simultaneous Effects of Temperature Variations and Sea Waves Clash. J. Mar. Sci. Eng. 2021, 9, 1433. https://doi.org/ $10.3390 /$ jmse9121433

Academic Editor: José A. F. O. Correia

Received: 6 November 2021

Accepted: 29 November 2021

Published: 15 December 2021

Publisher's Note: MDPI stays neutral with regard to jurisdictional claims in published maps and institutional affiliations.

Copyright: (c) 2021 by the authors Licensee MDPI, Basel, Switzerland. This article is an open access article distributed under the terms and conditions of the Creative Commons Attribution (CC BY) license (https:// creativecommons.org/licenses/by/ $4.0 /)$.
Abstract: In the present study, the authors attempted to predict the fatigue lifetime of a real-scale integral concrete bridge with $\mathrm{H}$-shaped steel piles resulting from working and environmental conditions. In this regard, various types of nonproportional variable amplitude loads were applied on the bridge, such as temperature variations and sea waves clash. To this end, CATIA software was used to model the real-scale bridge with its accessories, such as a concrete deck, concrete anchors (walls), I-shaped concrete beams (Ribs), and steel piles. Subsequently, stress analysis was performed to determine the critical area apt to fail. The results showed that steel piles are the most critical bridge components. As a result, in future analysis, the purpose will be to study this critical area, and the effect of relative humidity on the fatigue properties of concrete was ignored. Subsequently, the time history of stress tensor components in the critical area was obtained by performing transient dynamic analysis. Various well-known equivalent stress fatigue theories (von Mises, Findley, Dang Van, McDiarmid, Carpinteri-Spagnoli, Modified Findley, Modified McDiarmid, and Liu-Zenner) were utilized to calculate the equivalent stress caused by the simultaneous effect of temperature variations and sea waves clash. Eventually, the fatigue life of the structure was predicted by employing the rainflow counting algorithm and the Palmgren-Miner damage accumulation rule. The results indicated a reduction in the multiaxial fatigue life of the structure under the simultaneous effects of two phenomena, the daily temperature variations and the sea waves clash, of approximately $87 \%$ and $66 \%$, respectively, compared with the fatigue life of the structure under either the effect of temperature changes or the effect of sea waves clash, separately. Therefore, it was necessary to consider all the cyclic loads in the structural design step to estimate the fatigue life of the structure. Moreover, the findings of this case study revealed that the lowest value of multiaxial fatigue lifetime is related to the application of the Liu-Zenner criterion. In other words, this criterion is more conservative than the other used criteria.

Keywords: fatigue life; multiaxial fatigue; nonproportional VAL; integral concrete bridge; temperature variations; sea waves clash

\section{Introduction}

The occurrence of the fatigue phenomenon in engineering structures, including buildings and bridges, is undeniable. These structures are subject to various cyclic loads that, in the long run, lead to material damage that, after a while, reaches a critical value, ultimately resulting in the final structural failure. A great deal of research has been conducted to estimate the service life of the engineering structures and components under different working conditions and various types of dynamic loads [1-3]. Based on their results, the 
inspection time and quality parameters were recommended and subsequently used in various problems [4-7]. Over the recent decades, the newly found solutions for improving the fatigue life of engineering structures, including surface treatments such as different types of Shot Peening (SP) process [8-13], were presented. A number of studies have indicated that the fatigue life of carbon metals can be increased by eight times using Conventional SP and Severe SP processes $[14,15]$. Moreover, to increase the efficiency of this process, numerous studies have been conducted aiming to optimize the SP process parameters [16,17]. However, most of the failures occurring in engineering structures, especially mechanical parts, are due to cyclic loads and fatigue damage in materials [18-20]. Thus, understanding the fatigue behavior of structures and estimating their service life is of particular importance.

Bridges, as well as roads, are one of the strategically developed infrastructural elements essential for transportation. They are affected by different dynamics and cyclic loads, depending on factors, such as geometry, dimensions, working conditions, installation conditions, and location, we well as weather conditions. Perhaps due to the sheer complexity of these issues, no comprehensive study was found to cover all the cases; the literature published so far has focused primarily on specific types of loading, as well as a few other influential factors described below.

For instance, the changing deck length of concrete integrated bridges, caused by temperature variations on the pressure exerted on the bridges' walls, was evaluated [21]. The study results showed that the pressure on the walls depends on the number of thermal cycles, suggesting that there is a linear and proportional relationship between the number of thermal cycles and the pressure on the bridge walls. The effect of soil-structure interaction on the vibrational behavior of integrated bridges was also studied [22]. The influence of different modes of soil-structure interaction on the vibrational behavior of the system was investigated, and the responses were compared to the structural response, independent of the soil-structure interaction factor. Arsoy presented a novel mathematical model for calculating the thermal response of bridges under repetitive loading to sine waveform [23]. Kong et al. numerically investigated the effects of temperature on integrated bridges using the Finite Element Simulation (FES) technique [24]. In their research, only the temperature distribution profile at the piles and their height was extracted. The rotation and displacement created in the piles, including strain and flexural pressure, were also reported. Finally, the system response was compared in different modes considering different boundary conditions. Amirahmad and Al-Sinaidi simulated FEM of integrated concrete bridges and analyzed them with respect to the daily and seasonal temperature changes [25]. However, the analyses were not dynamically performed but only statically, focusing on the maximum temperature. In other words, temperature changes were considered as the maximum temperature in each season; the influence of passing time on moving from one temperature to another is ignored, which can have a significant impact on the fatigue life of the structure. However, since the study focused only on the deformation extraction and did not analyze fatigue, the central hypothesis is acceptable. Abdollahnia et al. evaluated the low-cycle fatigue behavior of steel piles caused by temperature changes [26], employing the strain-life criterion for assessing fatigue lifetime of the component under displacement control loading (zero ratio and frequency of $1 \mathrm{~Hz}$ ). The simulation results presented a $6.5 \%$ discrepancy with the results of the fatigue test and were suitable for future studies.

Furthermore, the same authors predicted the fatigue life of $\mathrm{H}$ cross-section steel piles of an integral concrete bridge under different conditions of motionless water and sea waves clash [27]. In their study, the effects of relative humidity on the fatigue properties of concrete were ignored, only making predictions relating to the fatigue life of steel piles mounted in water. Also, the influence of corrosion due to seawater salinity has not been considered. The authors reported that motionless water could not lead to fatigue phenomenon in bridges, while the impact of sea waves clash could trigger a great deal of deformation in the steel piles, eventually causing fatigue damage and failure of bridges. They also predicted the fatigue life of steel piles brought on by the effect of water waves clash using the finite 
element analysis and probabilistic approach. Malajerdi et al. performed spectral analysis of the clashing waves' force on the marine structure in the frequency domain [28].

In the studies conducted to estimate the fatigue life of bridges, failure under thermal cyclic loads is due to temperature variations. This finding could be justified thought the fact that the rate of expansion and contraction of various materials is different and causes separation between the adhesion boundaries of different materials, which often appear as cracks on the bridge's deck or the connection of piles to their deck. It also occurs in areas where daily temperature changes occur in a broad spectrum and where the temperature difference between the hot and cold seasons of the year is significant. If the temperature changes are ignored, and the bridge is built on water, the most common causes of damage include corrosion due to seawater salinity and fatigue due to sea waves clash. Additionally, seawater contains sulfates that damage concrete. As the concrete layers are washed away by seawater, the porosity of the concrete increases and leads to a decrease in the concrete strength. However, the part of the concrete that is always in the water will suffer the least damage. Because of the blockage of concrete cavities due to the deposition of magnesium hydroxide (composed of the reaction of magnesium sulfate and calcium hydroxide), the penetration of seawater into the concrete is slow. However, the concrete in the area between the tidal levels is more exposed and drying intermittently, and is thus severely attacked by invasive agents in seawater. Therefore, one of the factors affecting the service life of concrete above seawater is moisture and its penetration into the concrete. Unfortunately, due to the software limitations and the complexity of chemical reaction simulation, this parameter is ignored in the analysis. An attempt can be made to cover the effects of this parameter in the calculations by using the reliability coefficient in the results (this coefficient should be achieved only by performing many different experiments). Shoukry et al. investigated the effects of temperature and moisture on the static properties of concrete [29]. They stated that with increasing humidity, the Poisson's coefficient does not change, but the elastic modulus and consequently the strength of concrete decreases.

The results of previous studies have indicated that motionless water does not affect the fatigue life of the bridge structure. Therefore, the leading cause of fatigue failure in such bridges is random loading (different wavelengths, different wave heights, and different directions). Thus, if the bridge is subjected to both temperature changes and wave impact, the service life of the structure will be much shorter compared to that in both cases mentioned above. However, no study was found to examine both factors. One of the most important reasons is that the combined and multiaxial load fatigue test is expensive. In addition, the experiment must be performed on a real or suitable scale, which is complex and challenging to achieve. There are also several problems related to the finite element simulation, for example, the differences in loading frequencies due to daily temperature changes and sea waves clash.

In summary, the literature mentioned above investigated the shortcomings of a comprehensive study predicting the multiaxial fatigue life of integrated concrete bridges under the simultaneous effects of variable amplitude loads and due to temperature changes and seawater collisions. Therefore, the authors attempted to assess the life service of this structure using different stress-based fatigue criteria. To this end, a methodology was presented for fatigue life prediction of large structures under different nonproportional variable/random amplitude loading conditions with the lowest computational cost and maximum accuracy. Moreover, for the first time, an efficient solution was provided to solve the finite element problem in considering these two factors, aiming to evaluate the fatigue life of the structure.

\section{Methodology}

To estimate the multiaxial fatigue life of a large structure with the aim of reducing computational costs and solution time, it is necessary first to identify the critical areas prone to failure. Subsequently, complex calculations should be performed only in critical areas $[7,30-32]$. In other words, the analysis of the entire structure is unnecessary. The 
critical areas are determined using stress analysis in each loading type separately and in combination (considering the maximum value). In this method, nodes/elements with the maximum values of stress components in different directions (stress tensor) and von Mises equivalent stress (an appropriate failure criterion for construction metals) are selected as critical zones [33]. In this regard, the stress tensor has nine components, while the number of stress components is reduced to six due to the homogeneous properties of the metal, which, together with a value for the von Mises stress equivalent, make a total of seven values to be evaluated. A maximum of seven critical nodes/elements will be reported in each type of the loading conditions. As a result, in this study, a maximum of 21 nodes/elements were selected, and all the fatigue calculations were performed on them. Seven were related to the structural analysis caused by sea waves clash, seven to the coupling structural-thermal analysis due to temperature variations, and seven to the simultaneous effect of the previous two analyzes. Figure 1 represents the critical zone determination algorithm in this case study.

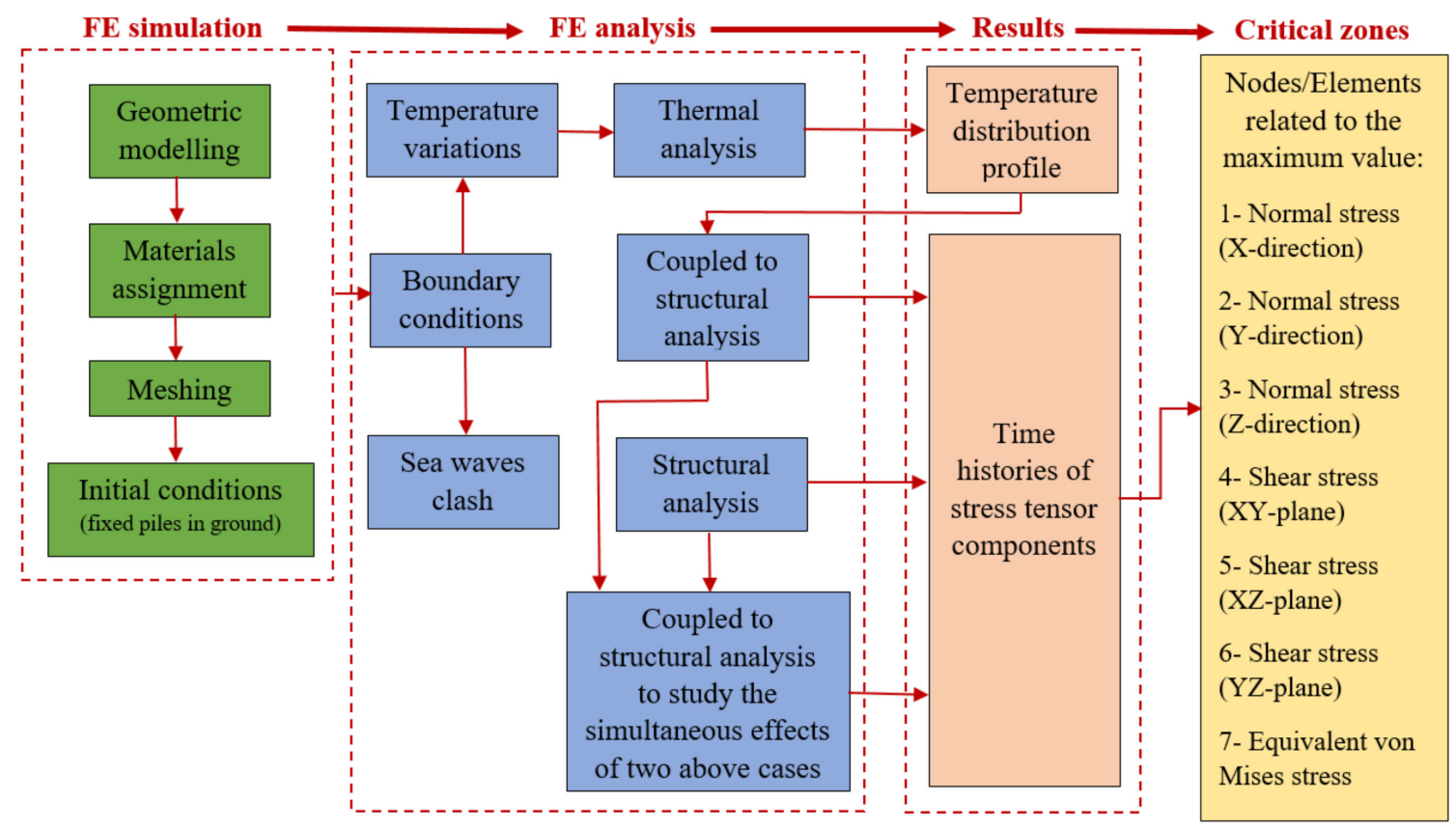

Figure 1. The proposed algorithm of the determination of critical nodes/elements in this case study.

It is also necessary to perform transient dynamic analyses in all three cases, including the effects of temperature variations, the sea waves clash, and the combination of both loads above. The time history of stress tensor components in all critical nodes should then be extracted. Subsequently, the equivalent stress history versus time is extracted employing various well-known equivalent stress fatigue methods, which were previously described in [33]. Eventually, the structure fatigue life due to multi-input random nonproportional 3D stress components was predicted employing the rainflow cycle counting technique and the Palmgren-Miner damage accumulation rule. Figure 2 depicts a general schematic of the fatigue life estimation process mentioned in the text. 


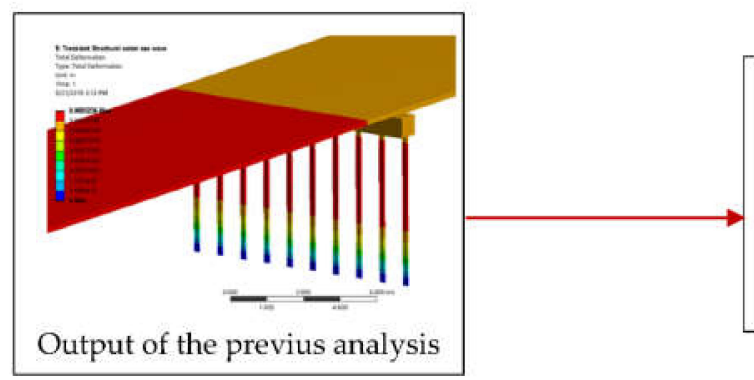

Choosing the critical near surface subspaces (elements/nodes) based on the stress intensity results Algorithm No. 1
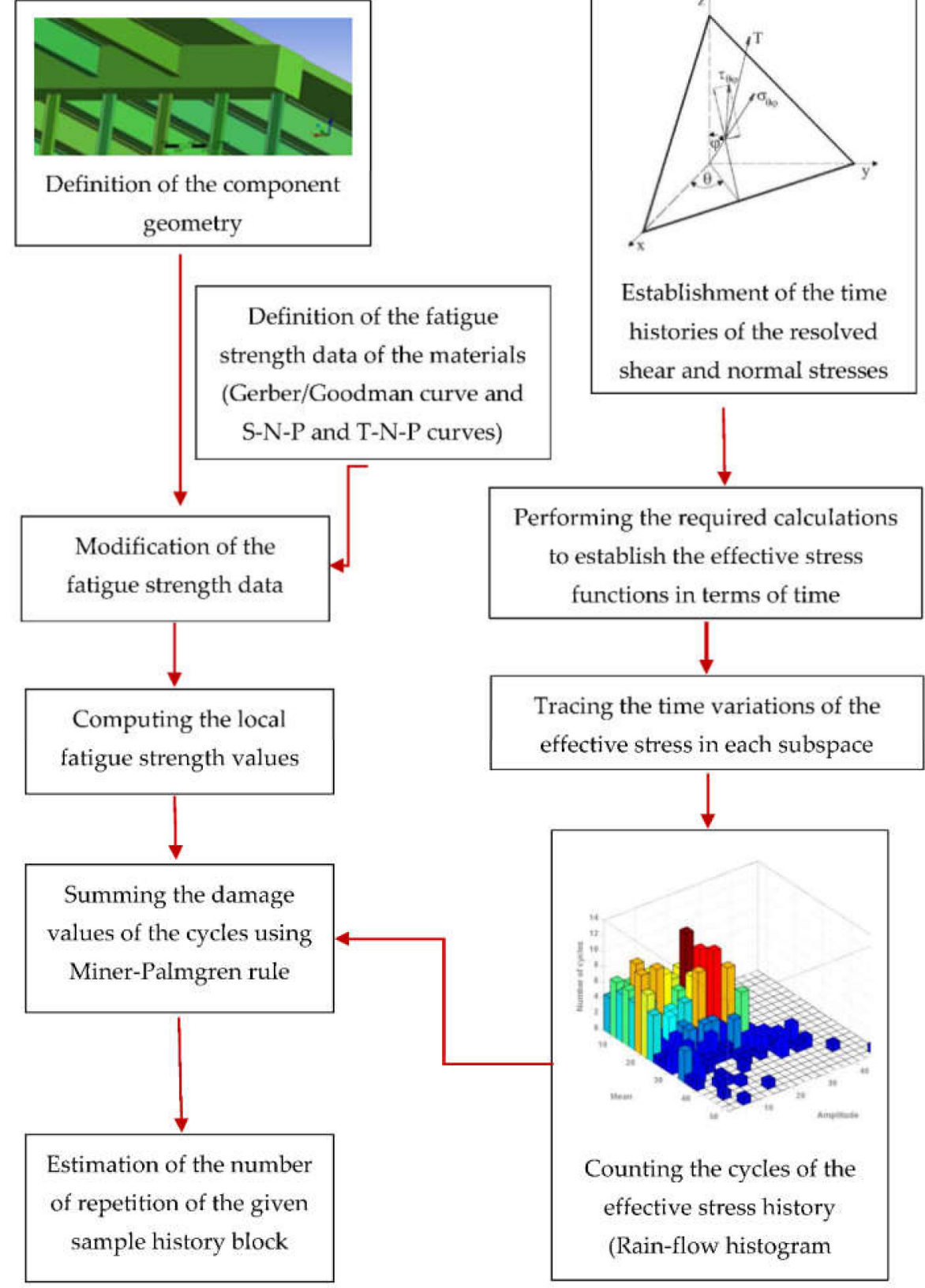

Figure 2. General schematic of the fatigue life estimation process used in this study.

\section{Geometry and Material}

In this case study, CATIA software was used to create 3D modeling of the bridge structure and its components, including the concrete deck, concrete anchors (walls), Ishaped concrete beams (Ribs), and steel piles. The assembly file was then inserted into 
the ANSYS WORKBENCH software (using *.stp file). This model consists of two middle pedestals, each of which includes ten steel piles. This model comprises 44 steel piles (type-IPE220). In addition, four rectangular concrete beams were considered for connecting steel piles to concrete material under the bridge's deck. Between each of these beams, I-shaped cross-section concrete beams (Ribs) with specifications equivalent to IPE600 were integrated into the concrete deck. These beams were divided into three sections: between the first wall and the first middle pedestals, between the first and second middle pedestals, and between the second middle pedestals and the second wall. Five Ribs at equal intervals were considered for each section (15 Ribs were modeled as integrated with the bridge's deck) [27]. Moreover, the steel piles' length was considered to be $6 \mathrm{~m}$. Furthermore, the width and length of the bridge deck, regardless of the concrete anchors and its accessories, were considered as 9.85 and $95.178 \mathrm{~m}$. The details of the geometric modeling of an integral concrete bridge are demonstrated in Figure 3.

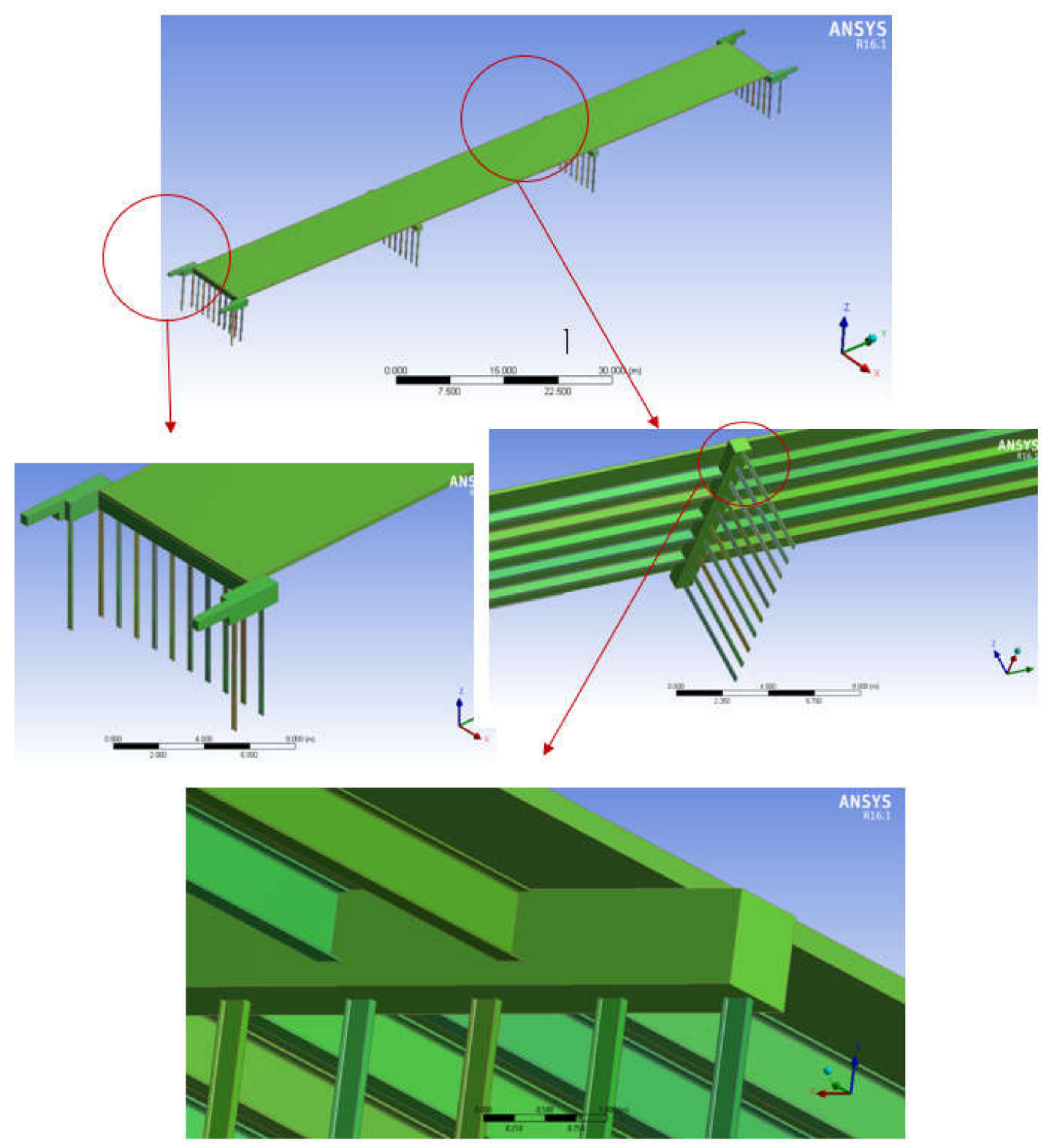

Figure 3. The details of the geometric model of an integrated concrete bridge with steel piles.

To investigate the integrated behavior of concrete parts, one group, including the geometries of the deck, middle beams, and I-shaped concrete beams (IPE 600), was defined 
in the FE software, which acts as a rigid part with no separation occurring between parts. However, their edges and surfaces were identifiable and could be applied separately for boundary conditions and loading.

Structural steel and ordinary concrete were utilized as the primary material in the present study. Tables 1 and 2 illustrate the mechanical and thermal characteristics, respectively, for both materials with the aim of structural, thermal, and coupling analyses.

Table 1. Mechanical characteristics of the primary materials used in this case study.

\begin{tabular}{cccc}
\hline \multirow{2}{*}{ Parameter } & Unit & \multicolumn{2}{c}{ Value } \\
\cline { 3 - 4 } & & Structural Steel & Concrete \\
\hline Density & $\mathrm{kg} / \mathrm{m}^{3}$ & 7850 & 2300 \\
Young Modulus & $\mathrm{GPa}$ & 200 & 30 \\
Poisson's Ratio & - & 0.3 & 0.18 \\
Bulk Modulus & $\mathrm{GPa}$ & 166 & - \\
Shear Modulus & $\mathrm{GPa}$ & 76.92 & - \\
Tensile Yield Stress & $\mathrm{Mpa}$ & 250 & - \\
Compressive Yield Stress & $\mathrm{Mpa}$ & 250 & 5 \\
Tensile Ultimate Strength & $\mathrm{Mpa}$ & 460 & 41 \\
\hline
\end{tabular}

Table 2. Thermal properties of the primary materials used in this case study.

\begin{tabular}{cccc}
\hline Parameter & Unit & Structural Steel & Concrete \\
\cline { 3 - 4 } & & 22 & 22 \\
$\begin{array}{c}\text { Reference } \\
\text { temperature } \\
\begin{array}{c}\text { Thermal expansion } \\
\text { coefficient }\end{array}\end{array}$ & $10^{-5} \times \frac{1}{{ }^{\circ} \mathrm{C}}$ & 1.2 & 1.4 \\
\hline
\end{tabular}

The results reported in the published papers have indicated that the fatigue failure occurs in steel piles as one of the most vulnerable components of the integrated bridge due to regular temperature variations. Therefore, the current study mainly focused on calculating the fatigue life of steel piles made with structural steel. Accordingly, only fatigue properties of construction steel in two regimes of High-Cycle Fatigue (HCF) and Low-Cycle Fatigue (LCF) were entered in the software, and the definition of concrete fatigue characteristics in the software was omitted [26,27]. Another reason is that the critical zone specified in this case study was related to steel piles. Hence, fatigue calculations were not performed on the entire structure. As a result, defining the fatigue properties of concrete in the software was unnecessary. Hereupon, the fatigue properties of construction steel were considered in both LCF (Table 3) and HCF regimes.

Table 3. LCF properties of structural steel based on the strain-life criterion [7].

\begin{tabular}{ccc}
\hline Parameter & Unit & Value \\
\hline Strength Coefficient & $\mathrm{Pa}$ & $9.2 \times 10^{8}$ \\
Strength Exponent & - & -0.106 \\
Ductility Coefficient & - & 0.213 \\
Ductility Exponent & - & -0.47 \\
Cyclic Strength Coefficient & $\mathrm{Pa}$ & $1 \times 10^{9}$ \\
Cyclic Strain Hardening & - & 0.2 \\
Exponent & & \\
\hline
\end{tabular}




\section{Finite Element Analysis \\ 4.1. Meshing Procedure}

In this research, solid rectangular elements were used to create a finite element model. However, this type of element should support thermal analysis as well as its structural coupling. Additionally, since all the components of the bridge structure are geometrically modeled in three dimensions, there was no need to use different types of elements such as beam elements, and the structure can be analyzed with high accuracy with solid elements only. Moreover, sensitivity analysis to the number of meshes was performed to obtain the size of the sides of the rectangular element so that by reducing the computational costs, the system responds with accuracy in the shortest possible time [34,35]. Full details of mesh convergence analysis in this case study are published in [27]. Figure 4 illustrates the FEM of the bridge and its components with 121,655 elements. For this purpose, the element size of the deck, wall, concrete beam under the deck, concrete I-shaped beam (IPE-600), and I-shaped steel piles (IPE-220) were considered to be 1, 0.5, 0.2, 0.2, and $0.2 \mathrm{~m}$, respectively [27].

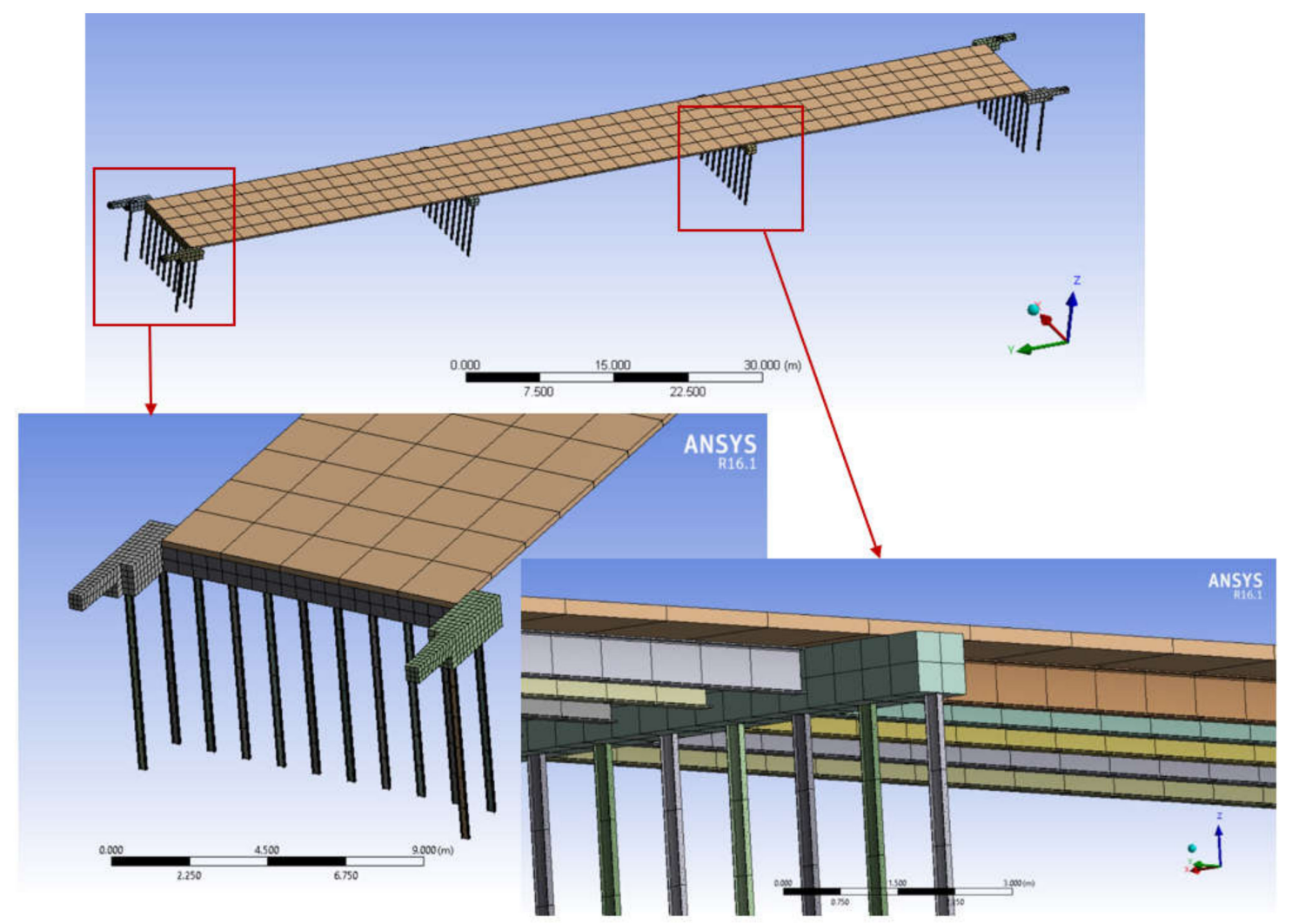

Figure 4. The FEM of the bridge and its components based on the results of sensitivity analysis.

\subsection{Initial, Boundary, and Loading Conditions}

Only fixing the steel piles in the soil was considered as the boundary condition. Thus, all the steel piles on both sides of the bridge and bottom surfaces of the piles related to the middle pedestals were constrained completely (six degrees of freedom) [27]. For thermal analysis, temperature variations were applied to the deck of the bridge (top surface of the structure) and caused changes in the deck's dimensions, specifically in its length. To this end, the temperature history as the maximum and minimum daily temperature were considered separately every month and during a year (Figure 5). It was also assumed that the temperature of steel piles is equal to the ambient temperature $\left(22^{\circ} \mathrm{C}\right)$. 


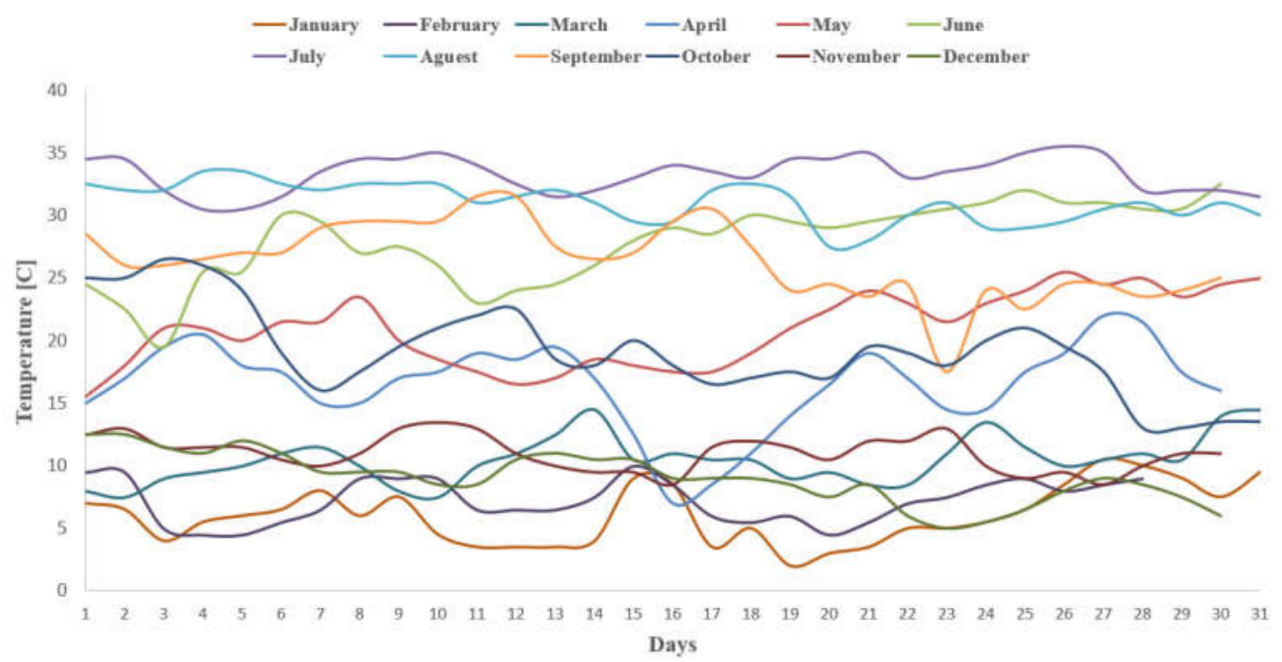

Figure 5. Average values of daily temperature changes in different months of the year.

No loading or additional boundary conditions need to be defined for structural analysis coupled to thermal analysis. It is only necessary to enter the thermal analysis response as the initial condition in the structural analysis. Nonetheless, for structural analysis to study the effect of sea waves clash on the fatigue behavior of the bridge, the wave height was assumed to be $25 \mathrm{~cm}$. Thus, the wave load was applied to the front surface of the middle piles in the positive X-direction, as shown in Figure 6. Furthermore, it should be noted that the height of the motionless water in the middle piles was considered to be $75 \mathrm{~cm}$. Moreover, water pressure in terms of height was applied to the structure, as shown in Figure 7.

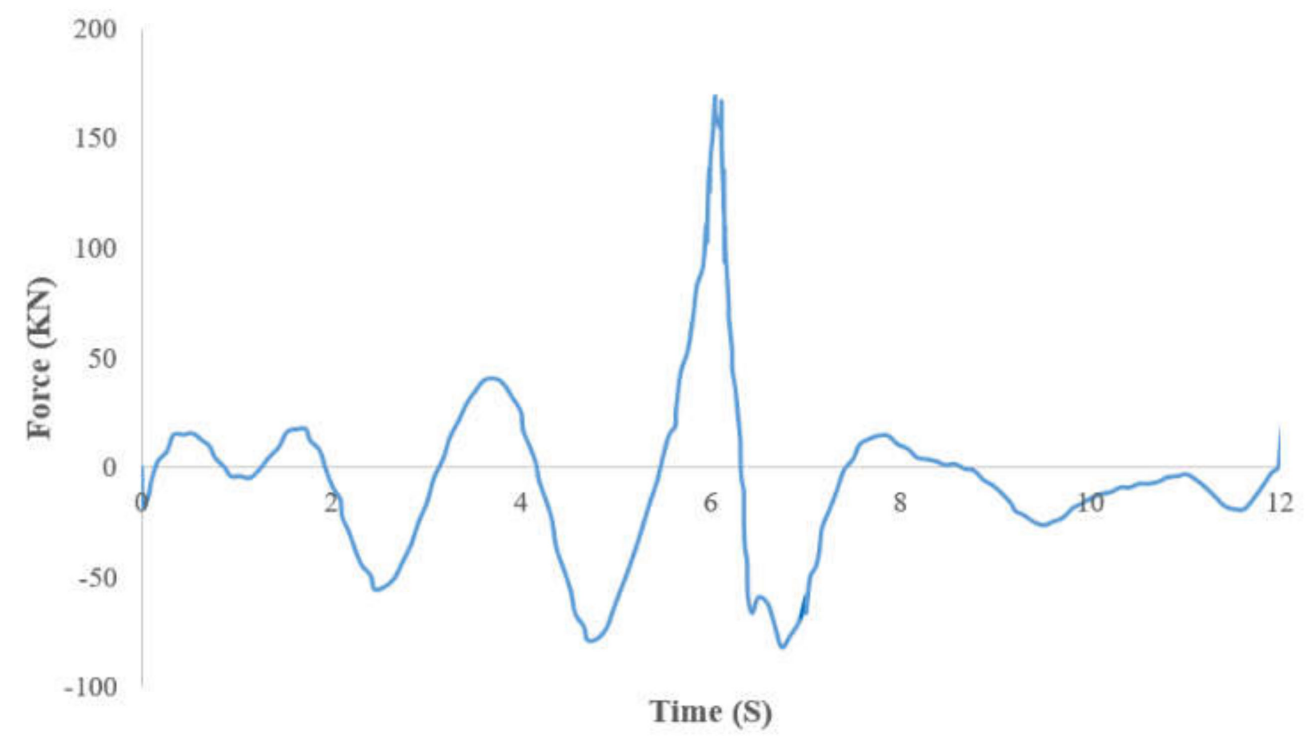

Figure 6. The force history used in this research as the sea waves clash to the middle steel piles [27]. 


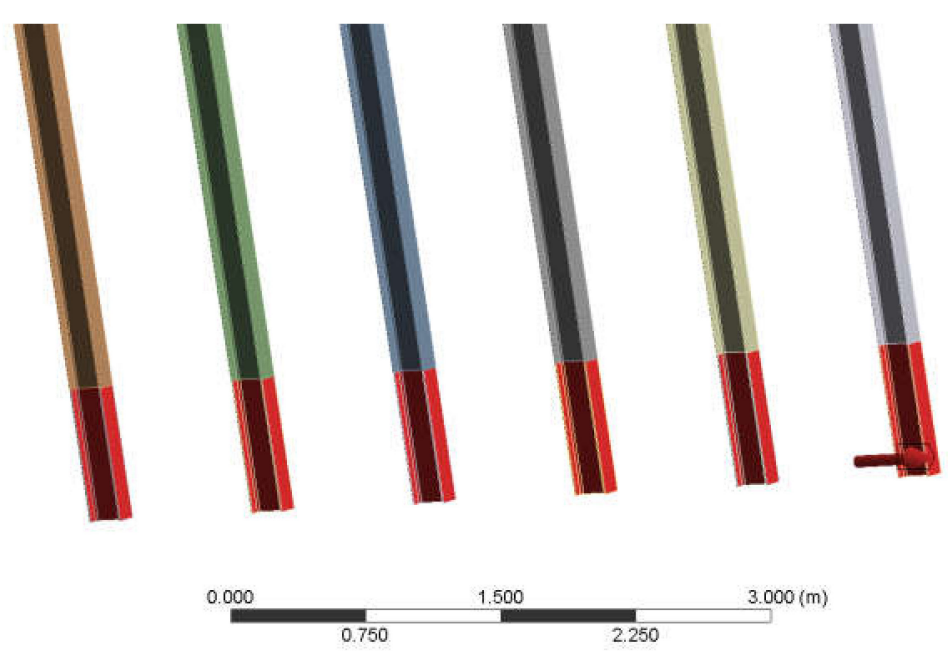

Figure 7. Scheme of the pressure applied to the middle steel piles of the bridge as a result of motionless water [27].

\subsection{Validation Process of the FEM in the Present Research}

Herein, the authors used a valid finite element model. Previously, they validated the proposed model by comparing results with experimental data [36]. For this purpose, a steel pile with a length of $1.9 \mathrm{~m}$ was studied under cyclic bending load due to the temperature changes. The bottom height of $0.4 \mathrm{~m}$ was fixed, and the top height of $0.15 \mathrm{~m}$ was loaded. According to the experiment results, the number of the cycles to failure under zero loading ratio, loading frequency of $1 \mathrm{~Hz}$, and displacement control method were 200, which is the average value of three repetitions of the test (194, 207, and 200). The finite element simulation result for the failure of $5 \%$ of the structure dimensions, which was equal to a crack with a length of $12 \mathrm{~mm}$, equaled 213 load cycles. This comparison implied the accuracy of the finite element model presented to predict the fatigue life of the structure close to reality (approximately 6.5\% difference). In summary, to avoid duplication, further details of the validation process were omitted and can be found in [26].

\subsection{Structural Analysis for Assessment of Sea Waves Clash Impact}

Transient analysis was performed, and the total deformation of the structure, which is related to the middle pedestals and the middle section of the concrete deck in the longitudinal direction, is demonstrated in Figure 8.

According to this figure, the upper part of the middle pedestals underwent the highest deformations in the structure (approximately $3.8 \mathrm{~m}$ from the upper part of the pedestals underwent severe deformation, and the bottom of the pedestals remained without deformation). Figure 9 presents the deformation history created in the critical area of the structure as the result of the current analysis.

\subsection{Coupling Structural-Thermal Analysis to Evaluate the Influence of Temperature Variations}

Transient thermal analysis was performed to obtain the profile of temperature distribution in all the components of the bridge during one year. To this end, the time interval between each temperature change was considered constant and equal to half of a day. Subsequently, the temperature profile was inputted into the structural analysis as an initial condition and applied on the nodes using Cartesian coordinates. Subsequently, transient dynamic analysis was performed to obtain the deflection of the deck length, and consequently, the skew of the upper part of steel piles was compared to its initial state. Figure 10 illustrates the longitudinal deformation of the deck in this case study. Moreover, the history of displacement changes versus different months is displayed in Figure 11. 


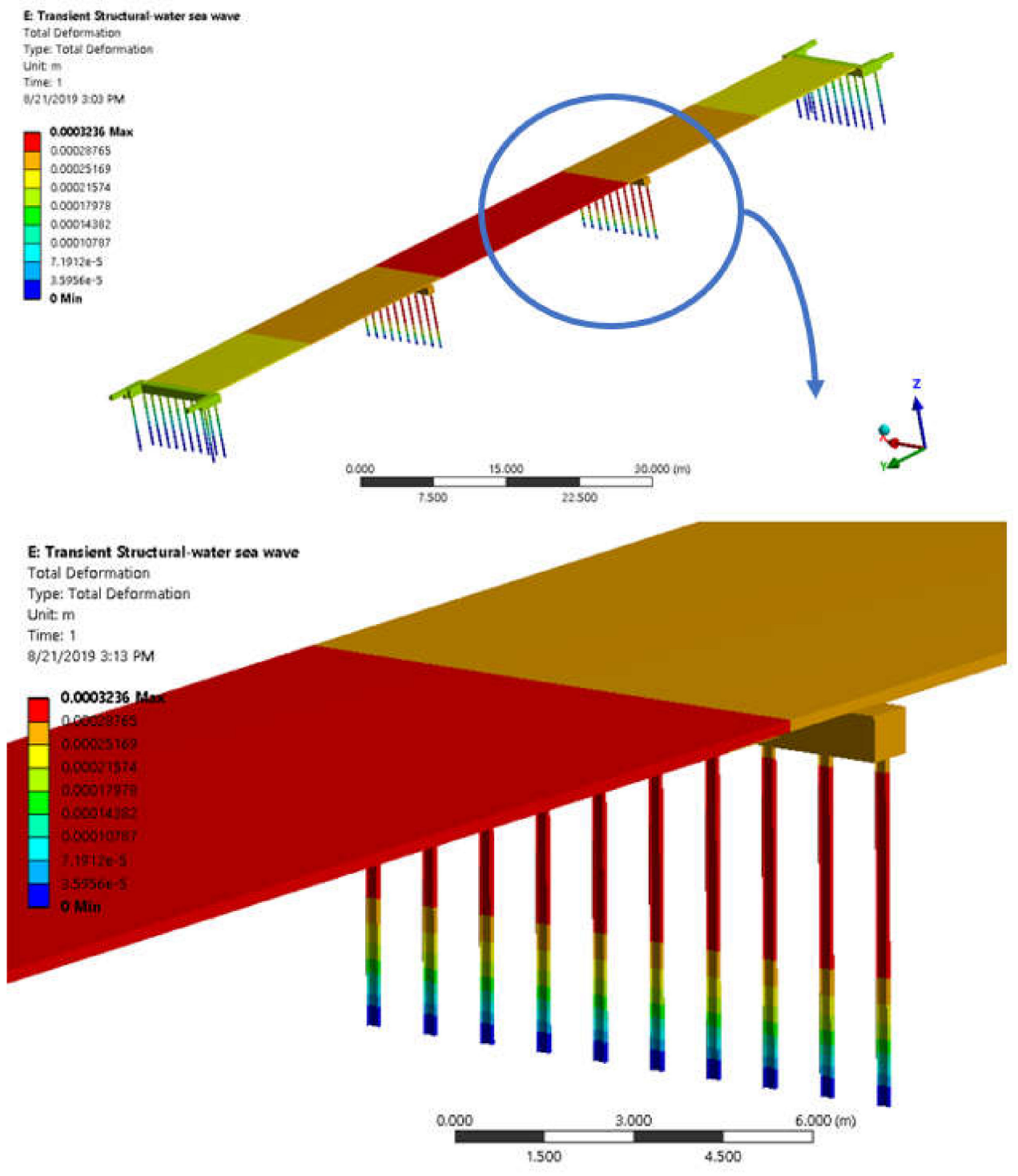

Figure 8. The total deformation of the integral concrete bridge with steel piles due to water waves clash [27].

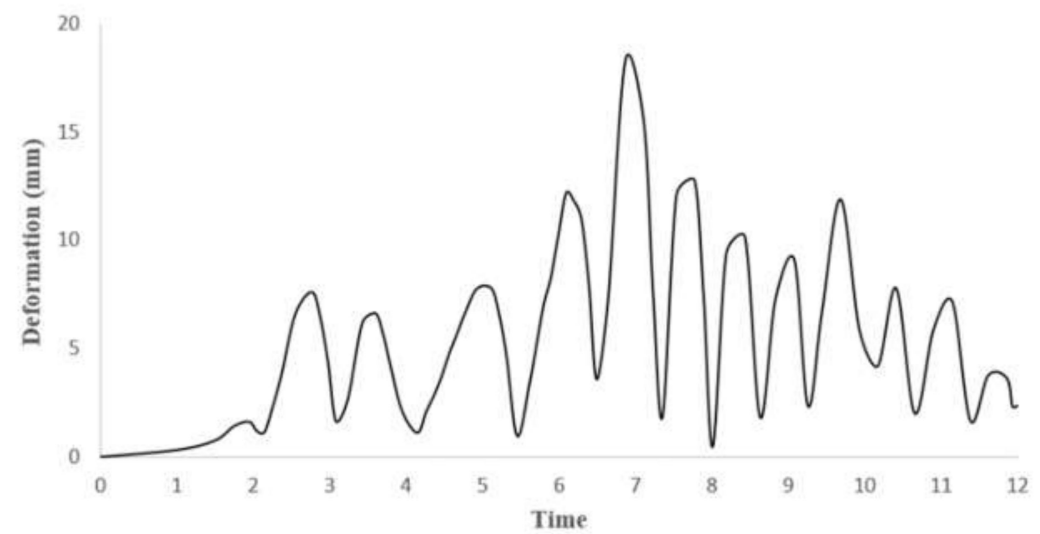

Figure 9. Time history of deformation created in the upper part of the middle pedestals [27]. 


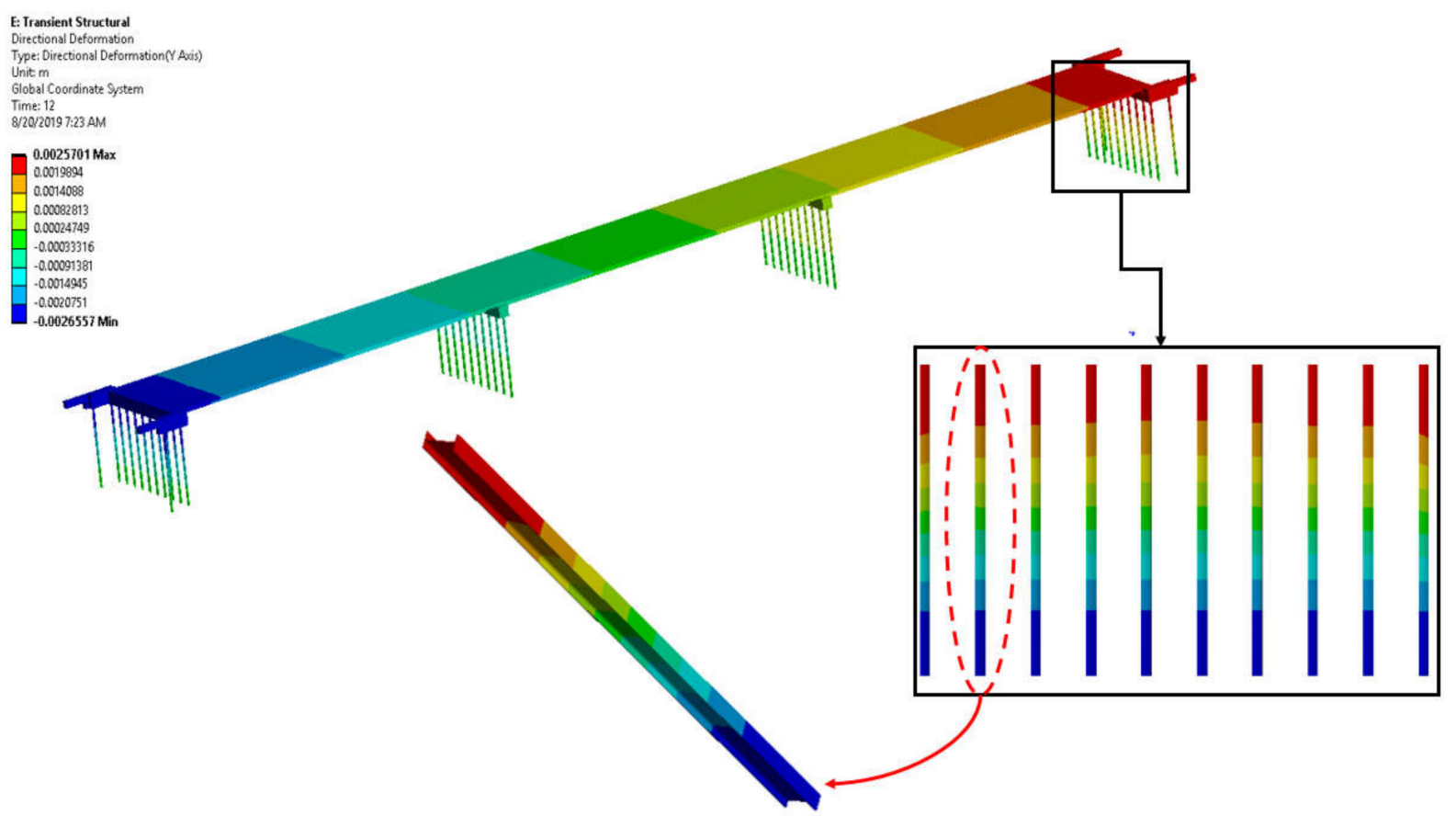

Figure 10. Longitudinal deformation of the deck due to the temperature variations during one year.

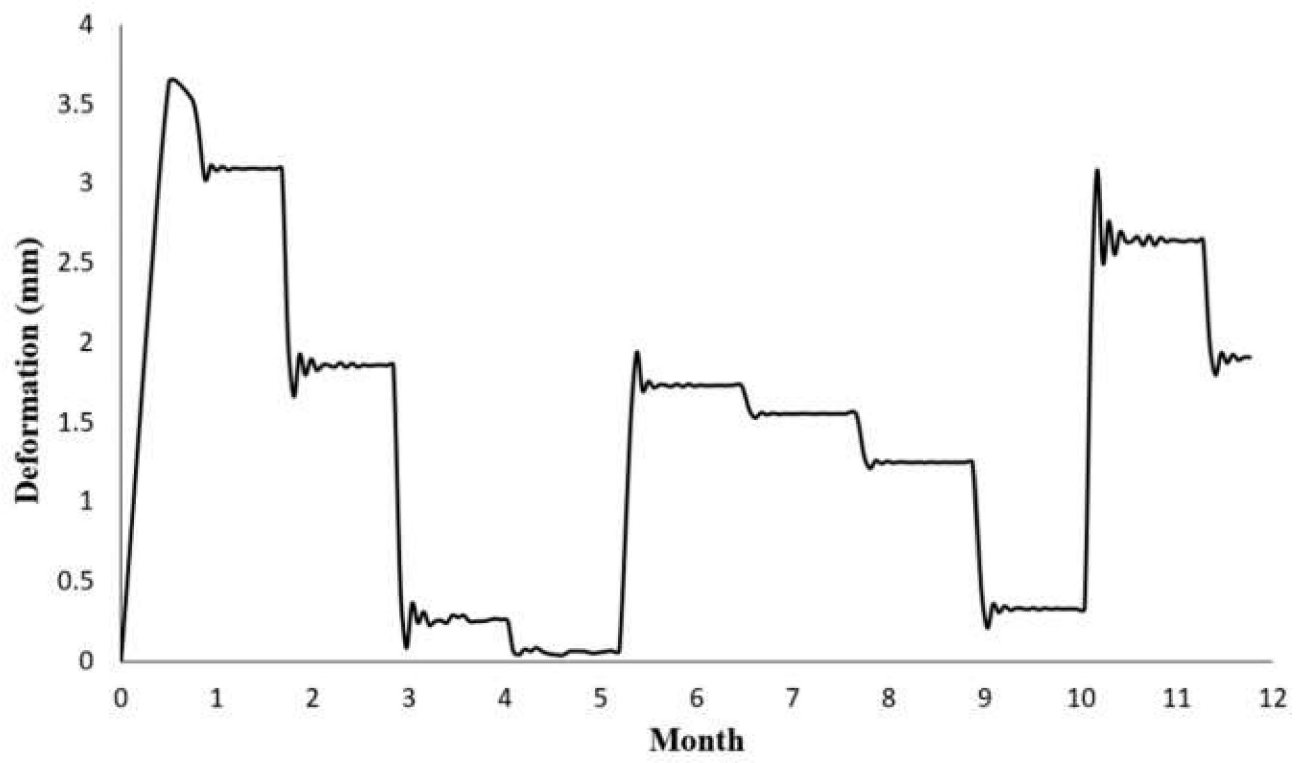

Figure 11. The history of displacement changes versus different months.

\subsection{Combination of the Two Above-Mentioned Cases}

In this section, both analyses mentioned above were performed separately. Their results were then entered as an initial condition in a blank structural analysis, and transient dynamics analysis was performed. Eventually, the desired outputs were extracted from the software and used in future calculations, including determining critical areas and fatigue life assessment.

\section{Fatigue Life Assessment}

Over the recent years and with the development in different sciences, such as mathematics, various cycle counting techniques have been presented. Nonetheless, researchers' findings have shown that applying the rainflow cycle counting method results in a more 
accurate response than other methods. Therefore, this cycle counting method was used to evaluate the equivalent stress block. After that, the fatigue damage was determined based on the Palmgren-Miner rule.

In sum, the time histories of stress components on the critical element were initially extracted. For example, Figure 12 presents the stress histories in element No. 38732 related to the coupling structural-thermal analysis to evaluate the influence of temperature variations.

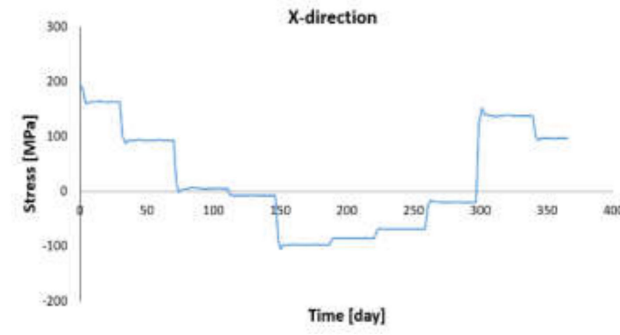

(a)

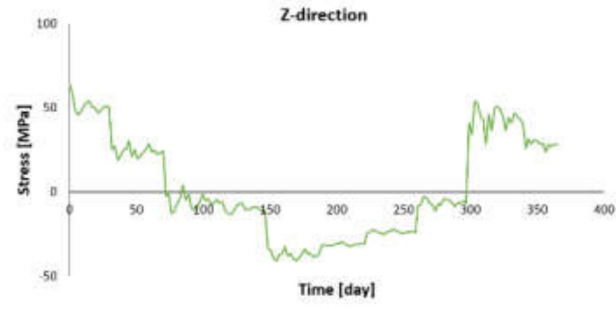

(c)

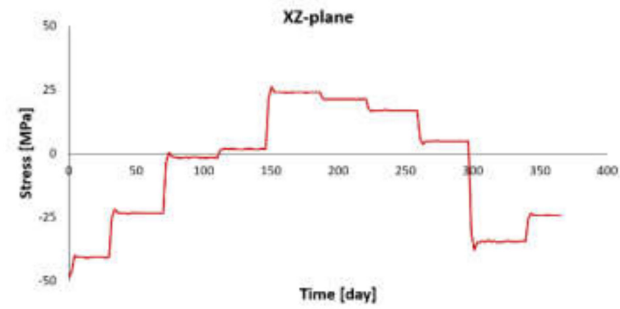

(e)

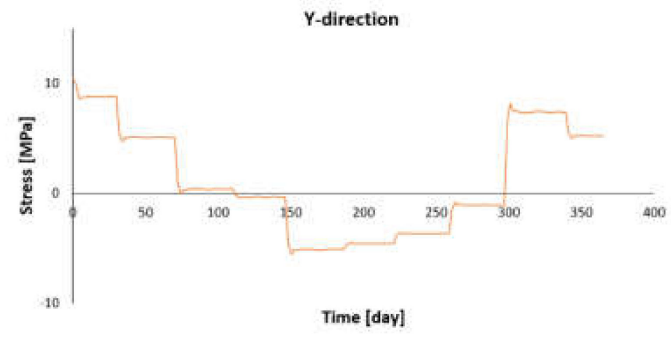

(b)

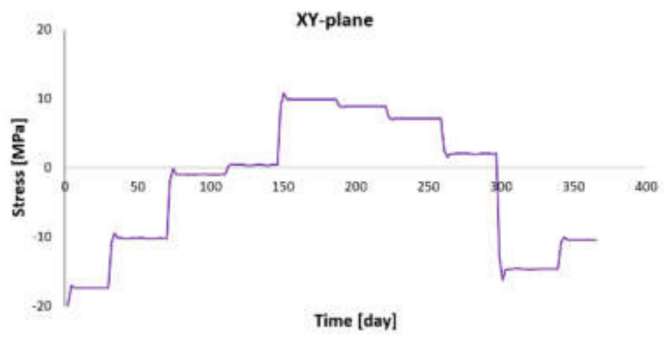

(d)

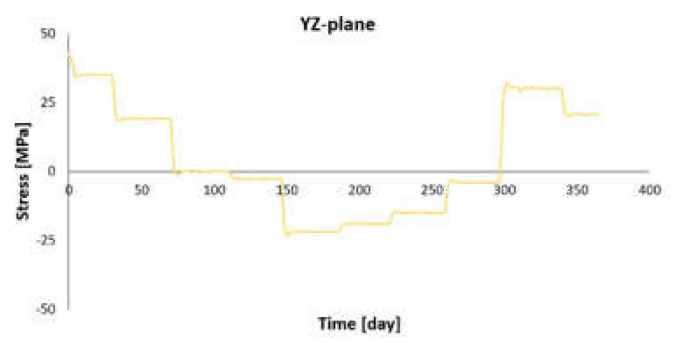

(f)

Figure 12. The time histories of stress components of Element No. 38732 due to temperature variations (coupling structuralthermal analysis), including (a) Normal stress in X-direction, (b) Normal stress in Y-direction, (c) Normal stress in Z-direction, (d) Shear stress in XY-plane, (e) Shear stress in XZ-plane, and (f) Shear stress in YZ-plane

The time history of equivalent stress was then calculated via different criteria of multiaxial equivalent stress (a complete description of them is provided in reference No. 32 by the third author). As a representative result, the equivalent stress diagrams for element No. 38732 in the coupling analysis to investigate the effect of temperature variations are illustrated in Figure 13. 


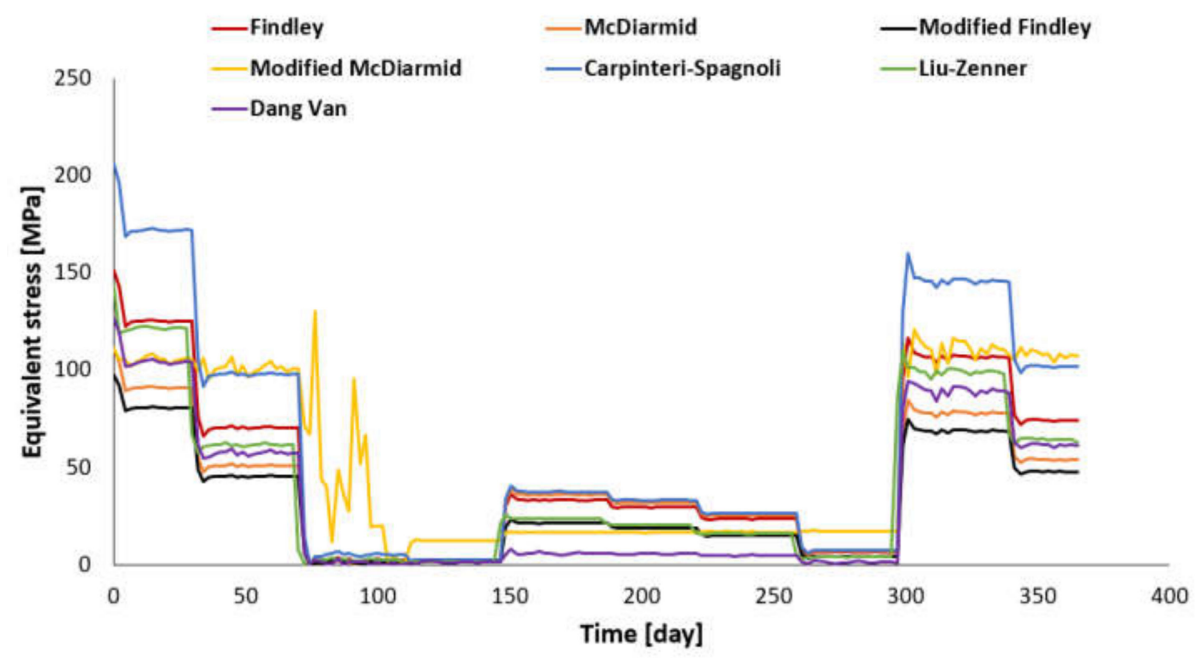

Figure 13. The time history of equivalent stress utilizing various criteria (element No. 38732 in the coupling structural-thermal analysis due to temperature variations).

Furthermore, the number of cycles of different equivalent stresses were counted employing the rainflow cycle counting algorithm [37] for element No. 38732, as reported in Table 4. Eventually, the fatigue damage was determined based on the Palmgren-Miner rule as one of the well-known Linear Damage Accumulation Rules (LDAR). The fatigue life was then calculated to be equal to one divided by the total damage.

Table 4. Cycle-counting results of the rainflow technique for different equivalent stresses in element No. 38732.

\begin{tabular}{cc}
\hline Definition Type of the Equivalent Fatigue Stress & Cycles \\
\hline Findley & 47 \\
McDiarmid & 48 \\
Dang van & 43 \\
Modified Findley & 47 \\
Modified McDiarmid & 55 \\
Carpinteri-Spagnoli & 48 \\
Liu-Zenner & 47 \\
\hline
\end{tabular}

\section{Results and Discussion}

\subsection{Critical Zones}

The results obtained from different types of finite element analyses described in Section 4 were used. Based on the algorithm shown in Figure 1 and the additional explanations given in Section 2, the critical nodes apt to fatigue failures were obtained and reported in Table 5.

Table 5. Elements with higher stress components and equivalent stress apt to fatigue failure.

\begin{tabular}{ccccccccc}
\hline Loading Conditions & Stress [Mpa] & $\sigma_{x}$ & $\sigma_{y}$ & $\sigma_{z}$ & $\sigma_{x y}$ & $\sigma_{y z}$ & $\sigma_{x z}$ & $\sigma_{v o n}$ \\
\hline \multirow{2}{*}{ Temperature variations } & Elem. No & 38,732 & 38,732 & 40,879 & 40,101 & 42,018 & 38,684 & 38,732 \\
& Value & 195.24 & 71.91 & 131.89 & 46.60 & 37.51 & 49.35 & 171.6 \\
& Elem. No & 56,042 & 56,203 & 61,308 & 61,234 & 56,177 & 56,180 & 5235 \\
Sea waves clash & Value & 239.1 & 142.2 & 135.56 & 51.7 & 61.7 & 52.4 & 194.3 \\
Combination of two & Elem. No & 56,042 & 56,203 & 61,308 & 61,234 & 56,177 & 56,180 & 5235 \\
above-mentioned cases & Value & 248.7 & 149.3 & 146.51 & 52.5 & 64.7 & 58.4 & 203 \\
\hline
\end{tabular}

The results revealed that all the critical elements are related to the upper part of the steel piles on either side of the bridge (concrete deck). However, only element No. 5235 
was in the middle of the steel piles. Therefore, fatigue calculations were performed on all the elements listed in Table 5.

\subsection{Fatigue Life of Steel Piles on the Integrated Concrete Bridge}

According to the methodology presented in the previous sections, the time histories of stress tensor components in all the critical elements (Table 5) were extracted from the software. Thereafter, using different criteria of multiaxial equivalent stress considering nonproportional loading such as Findley, Dang van, McDiarmid, Carpinteri-Spagnoli, Liu-Zenner, and modified Findley and McDiarmid, the time history of equivalent stress in the critical elements was calculated. Meanwhile, the loading conditions of temperature variations led to proportional 3D stresses in the critical elements. However, the other two loading conditions (sea waves clash and its combination with temperature variations) led to nonproportional 3D stresses in the critical elements. Finally, all the steps described in Section 5 (element No. 38732) were repeated for all the critical elements reported in Table 5. The smallest amount of fatigue life was then introduced as the fatigue life of the structure, and the corresponding element was reported as the failure location.

The shortest fatigue life was found to be related to element No. 56203. In this element, the maximum stress was obtained in the Y-direction, which was the longitudinal direction of the deck. In other words, the bending phenomenon occurred on the top of the steel piles, and the predominant load was the cyclic load due to bending at the end of a free-fixed beam. Fatigue lives in terms of the number of repetitions of the sample time histories for different fatigue criteria, and element No. 56203 is demonstrated in Figure 14.

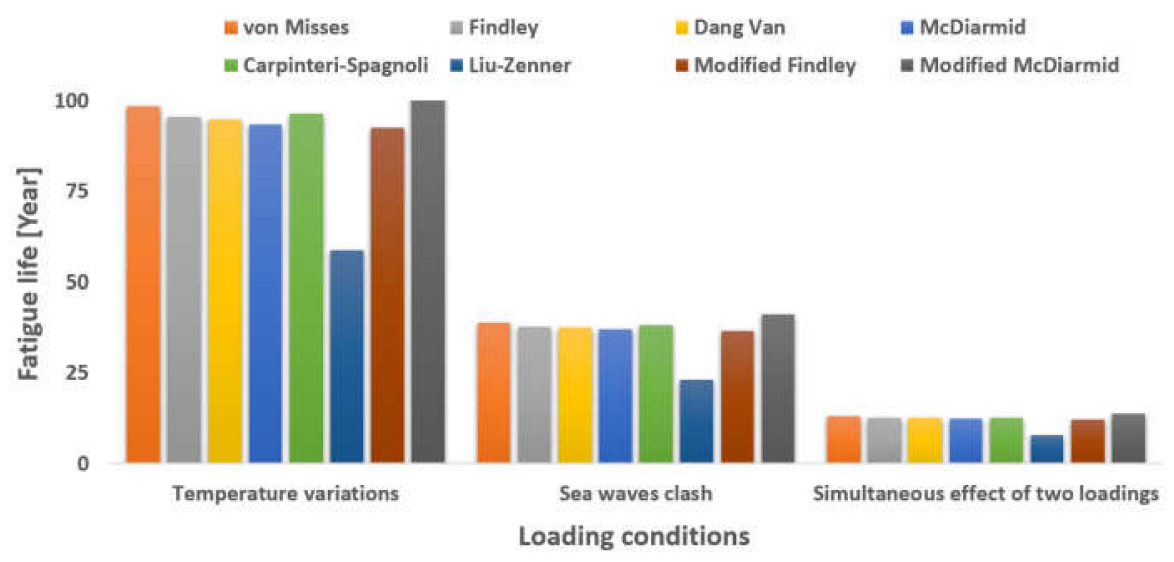

Figure 14. The fatigue lives predicted by various fatigue criteria in the top part of the steel piles as the critical zone (element No. 56203).

Based on Figure 14, it is clear that the difference in the fatigue life of the integrated concrete bridge determined by applying different criteria under simultaneous loading conditions, such as a combination of temperature variations, and sea waves clash, could be negligible. In other words, the type of criterion has little effect on the response. However, the lowest value of multiaxial fatigue lifetime belonged to the application of the Liu-Zenner criterion. It means that this criterion is more conservative than the others. In addition, the results obtained herein indicated that, to reduce computational costs and avoid complex calculations which may lead to computational error, the von Mises equivalent stress criterion can be used with acceptable accuracy. According to the Liu-Zenner criterion, the fatigue life of bridge steel piles under loading conditions of temperature variations, sea waves clash, and both loads simultaneously were estimated at 58.71, 23.25, and 7.75 years, respectively. Nevertheless, this value equaled 98.5, 39, and 13 years, respectively, obtained using the von Mises equivalent stress criterion. However, Mozafari et al. developed sophisticated plasticity-based models for evaluating the fatigue life of metallic materials under multiaxial proportional and nonproportional loading conditions [38,39]. Therefore, one of the future plans of the authors is to predict the fatigue lifetime of bridge structure as 
a case study by employing new methods and compare the results with the achievements of the current research.

\section{Conclusions}

In the current study, a comprehensive comparison was made between the results of different categories of the fatigue life assessment criteria. To this end, the case study of an integrated concrete bridge with steel piles was considered. Furthermore, a fatigue life assessment algorithm was proposed considering a complicated geometry under a multipoint 3D nonproportional input. The following practical findings could be reported based on the presented discussions and comparisons:

1. The results of the structural analysis related to the sea waves clash indicated that the upper part of the middle pedestals underwent the highest deformations in the structure. The height of $3.8 \mathrm{~m}$ from the upper part of the pedestals underwent severe deformation, and the bottom of the pedestals remained without deformation (the height of $40 \mathrm{~cm}$ from the bottom).

2. The results of the analyses revealed that all the critical elements are related to the upper part of the steel piles on either side of the bridge.

3. The shortest fatigue life was related to the element with the maximum value of Ydirection stress (the longitudinal direction of the deck). The predominant load was the cyclic load due to bending at the top of the steel piles.

4. The present study revealed that the lowest value of multiaxial fatigue lifetime belonged to the application of the Liu-Zenner criterion. In other words, the Liu-Zenner criterion is more conservative than the others.

5. To reduce computational costs and avoid complex calculations, which may lead to computational error, the von Mises equivalent stress criterion was found to be useful with acceptable accuracy.

6. The fatigue life of bridge steel piles under loading conditions of temperature variations, sea waves clash, and both loads simultaneously was estimated at 58.71, 23.25, and 7.75 years, respectively.

7. The results indicated that the multiaxial fatigue life of the structure under the simultaneous effects of the two phenomena of daily temperature variations and the sea waves clash is reduced by approximately $87 \%$ and $66 \%$, respectively, compared to the fatigue life of the structure under the effect of temperature changes and the effect of sea waves clash separately.

Author Contributions: Conceptualization, K.R.K.; methodology, K.R.K. and M.H.A.E.; software, H.A. and K.R.K.; validation, H.A.; formal analysis, H.A. and K.R.K.; investigation, H.A. and M.H.A.E.; resources, K.R.K.; data curation, H.A., M.H.A.E., and K.R.K.; writing—original draft preparation, H.A. and M.H.A.E.; writing-review and editing, K.R.K.; visualization, H.A. and M.H.A.E.; supervision, K.R.K.; project administration, M.H.A.E.; funding acquisition, K.R.K. and H.A. All authors have read and agreed to the published version of the manuscript.

Funding: This research received no external funding.

Institutional Review Board Statement: Not applicable.

Informed Consent Statement: Informed consent was obtained from all subjects involved in the study.

Data Availability Statement: The data that support the findings of this study are available from the corresponding author upon reasonable request.

Acknowledgments: This paper has been supported by the RUDN University Strategic Academic Leadership Program.

Conflicts of Interest: The authors declare no conflict of interest. 


\section{References}

1. Farrahi, G.H.; Ahmadi, A.; Kashyzadeh, K.R. Simulation of vehicle body spot weld failures due to fatigue by considering road roughness and vehicle velocity. Simul. Model. Pract. Theory 2020, 105, 102168. [CrossRef]

2. Ahmadi, A.; Farrahi, G.H.; Kashyzadeh, K.R.; Azadi, S.; Jahani, K. A comparative study on the fatigue life of the vehicle body spot welds using different numerical techniques: Inertia relief and Modal dynamic analyses. Frat. Integrità Strutt. 2020, 14, 67-81.

3. Nouri, M.; Ashenai-Ghasemi, F.; Rahimi-Sherbaf, G.; Kashyzadeh, K.R. Experimental and numerical study of the static performance of a hoop-wrapped CNG composite cylinder considering its variable wall thickness and polymer liner. Mech. Compos. Mater. 2020, 56, 339-352. [CrossRef]

4. Ge, B.; Kim, S. Probabilistic service life prediction updating with inspection information for RC structures subjected to coupled corrosion and fatigue. Eng. Struct. 2021, 238, 112260. [CrossRef]

5. Amiri, N.; Farrahi, G.H.; Kashyzadeh, K.R.; Chizari, M. Applications of ultrasonic testing and machine learning methods to predict the static \& fatigue behavior of spot-welded joints. J. Manuf. Process. 2020, 52, 26-34.

6. Ge, B.; Kim, S. Determination of appropriate updating parameters for effective life-cycle management of deteriorating structures under uncertainty. Struct. Infrastruct. Eng. 2021, 17, 1284-1298. [CrossRef]

7. Kashyzadeh, K.R.; Rahimian Koloor, S.S.; Omidi Bidgoli, M.; Petrů, M.; Amiri Asfarjani, A. An Optimum Fatigue Design of Polymer Composite Compressed Natural Gas Tank Using Hybrid Finite Element-Response Surface Methods. Polymers 2021, 13, 483. [CrossRef] [PubMed]

8. Soyama, H.; Chighizola, C.R.; Hill, M.R. Effect of compressive residual stress introduced by cavitation peening and shot peening on the improvement of fatigue strength of stainless steel. J. Mater. Process. Technol. 2021, 288, 116877. [CrossRef]

9. Karimbaev, R.; Pyun, Y.S.; Maleki, E.; Unal, O.; Amanov, A. An improvement in fatigue behavior of AISI 4340 steel by shot peening and ultrasonic nanocrystal surface modification. Mater. Sci. Eng. A 2020, 791, 139752. [CrossRef]

10. Maleki, E.; Unal, O.; Kashyzadeh, K.R.; Bagherifard, S.; Guagliano, M. A systematic study on the effects of shot peening on a mild carbon steel: Microstructure, mechanical properties, and axial fatigue strength of smooth and notched specimens. Appl. Surf. Sci. Adv. 2021, 4, 100071. [CrossRef]

11. Maleki, E.; Unal, O.; Guagliano, M.; Bagherifard, S. The effects of shot peening, laser shock peening and ultrasonic nanocrystal surface modification on the fatigue strength of Inconel 718. Mater. Sci. Eng. A 2021, 810, 141029. [CrossRef]

12. Soyama, H. Comparison between the improvements made to the fatigue strength of stainless steel by cavitation peening, water jet peening, shot peening and laser peening. J. Mater. Process. Technol. 2019, 269, 65-78. [CrossRef]

13. Maleki, E.; Farrahi, G.H.; Kashyzadeh, K.R.; Unal, O.; Guagliano, M.; Bagherifard, S. Effects of conventional and severe shot peening on residual stress and fatigue strength of steel AISI 1060 and residual stress relaxation due to fatigue loading: Experimental and numerical simulation. Met. Mater. Int. 2021, 27, 2575-2591. [CrossRef]

14. Maleki, E.; Unal, O.; Kashyzadeh, K.R. Effects of conventional, severe, over, and re-shot peening processes on the fatigue behavior of mild carbon steel. Surf. Coat. Technol. 2018, 344, 62-74. [CrossRef]

15. Maleki, E.; Unal, O.; Kashyzadeh, K.R. Fatigue behavior prediction and analysis of shot peened mild carbon steels. Int. J. Fatigue 2018, 116, 48-67. [CrossRef]

16. Maleki, E.; Unal, O.; Kashyzadeh, K.R. Efficiency analysis of shot peening parameters on variations of hardness, grain size and residual stress via Taguchi approach. Met. Mater. Int. 2019, 25, 1436-1447. [CrossRef]

17. Maleki, E.; Unal, O.; Kashyzadeh, K.R. Surface layer nanocrystallization of carbon steels subjected to severe shot peening: Analysis and optimization. Mater. Charact. 2019, 157, 109877. [CrossRef]

18. Kashyzadeh, K.R.; Arghavan, A. Study of the effect of different industrial coating with microscale thickness on the CK45 steel by experimental and finite element methods. Strength Mater. 2013, 45, 748-757. [CrossRef]

19. Arghavan, A.; Reza Kashyzadeh, K.; Asfarjani, A.A. Investigating effect of industrial coatings on fatigue damage. Appl. Mech. Mater. 2011, 87, 230-237. [CrossRef]

20. Kashyzadeh, K.R.; Maleki, E. Experimental investigation and artificial neural network modeling of warm galvanization and hardened chromium coatings thickness effects on fatigue life of AISI 1045 carbon steel. J. Fail. Anal. Prev. 2017, 17, $1276-1287$. [CrossRef]

21. Movahedifar, M.; Bolouri Bazaz, J.; Jafari, M.K. Influence of thermal elongation of integrated bridge deck on the amount of pressure applied to the bridges. In Proceedings of the 6th International Congress of Civil Engineering, Semnan, Iran, 26 April 2011. (In Persian).

22. Najafi, H. Investigation of the influence of height deck on the behavioral parameters of integrated bridge retaining piles in clay soils with rock shallow floor. In Proceedings of the 10th International Congress of Civil Engineering, Tabriz, Iran, 29 April 2015. (In Persian).

23. Arsoy, S. Proposed mathematical model for daily and seasonal thermal bridge displacements. Transp. Res. Rec. 2008, 16, 3-12. [CrossRef]

24. Kong, B.; Cai, C.S.; Zhang, Y. Parametric study of an integral abutment bridge supported by prestressed precast concrete piles. Eng. Struct. 2016, 120, 37-48. [CrossRef]

25. Amirahmad, A.; Al-Sinaidi, A.R. Analysis of Integral Bridges by Finite Element Method, the 2nd International Conference on Rehabilitation and Maintenance in Civil Engineering. Procedia Eng. 2013, 54, 308-314. [CrossRef] 
26. Abdollahnia, H.; Alizadeh Elizei, M.H.; Reza Kashyzadeh, K. Low-cycle fatigue behavior of H-shaped steel piles of an integral concrete bridge subjected to temperature variations. Mater. Today Proc. 2021, 46, 1657-1662. [CrossRef]

27. Abdollahnia, H.; Alizadeh Elizei, M.H.; Reza Kashyzadeh, K. Fatigue life assessment of integral concrete bridges with H cross-section steel piles mounted in water. J. Fail. Anal. Prev. 2020, 20, 1661-1672. [CrossRef]

28. Malajerdi, A.; Jahanmard, V.R.; Tabeshpour, M.R. Spectral analysis of impact waves on marine structures. In Proceedings of the Sixth International Conference on Offshore Industries, Tehran, Iran, 4-5 May 2015. (In Persian).

29. Shoukry, S.N.; William, G.W.; Downie, B.; Riad, M.Y. Effect of moisture and temperature on the mechanical properties of concrete. Constr. Build. Mater. 2011, 25, 688-696. [CrossRef]

30. Kashyzadeh, K.R. A new algorithm for fatigue life assessment of automotive safety components based on the probabilistic approach: The case of the steering knuckle. Eng. Sci. Technol. Int. J. 2020, 23, 392-404. [CrossRef]

31. Farrahi, G.H.; Chamani, M.; Kashyzadeh, K.R.; Mostafazade, A.; Mahmoudi, A.H.; Afshin, H. Failure analysis of bolt connections in fired heater of a petrochemical unit. Eng. Fail. Anal. 2018, 92, 327-342. [CrossRef]

32. Reza Kashyzadeh, K.; Farrahi, G.H.; Shariyat, M.; Ahmadian, M.T. The Role of Wheel Alignment Over the Fatigue Damage Accumulation in Vehicle Steering Knuckle. J. Stress Anal. 2018, 3, 21-33.

33. Kashyzadeh, K.R.; Farrahi, G.H.; Shariyat, M.; Ahmadian, M.T. Experimental accuracy assessment of various high-cycle fatigue criteria for a critical component with a complicated geometry and multi-input random non-proportional 3D stress components. Eng. Fail. Anal. 2018, 90, 534-553. [CrossRef]

34. Omidi Bidgoli, M.; Kashyzadeh, K.R.; Rahimian Koloor, S.S.; Petru, M.; Amiri, N. Optimum design of sunken reinforced enclosures under buckling condition. Appl. Sci. 2020, 10, 8449. [CrossRef]

35. Reza Kashyzadeh, K.; Farrahi, G.H.; Shariyat, M.; Ahmadian, M.T. Experimental and finite element studies on free vibration of automotive steering knuckle. Int. J. Eng. 2017, 30, 1776-1783.

36. Karalar, M.; Dicleli, M. Effect of thermal induced flexural strain cycles on the low cycle fatigue performance of integral bridge steel H-piles. Eng. Struct. 2016, 124, 388-404. [CrossRef]

37. Nieslony, A. Determination of fragments of multiaxial service loading strongly influencing the fatigue of machine components. Mech. Syst. Signal Pract. 2009, 23, 2712-2721. [CrossRef]

38. Mozafari, F.; Thamburaja, P.; Srinivasa, A.; Abdullah, S. Fatigue life prediction under variable amplitude loading using a microplasticity-based constitutive model. Int. J. Fatigue 2020, 134, 105477. [CrossRef]

39. Mozafari, F.; Thamburaja, P.; Moslemi, N.; Srinivasa, A. Finite-element simulation of multi-axial fatigue loading in metals based on a novel experimentally-validated microplastic hysteresis-tracking method. Finite Elem. Anal. Des. 2021, 187, 103481. [CrossRef] 